\title{
Comparative study of liver biopsy results in egypt over three decades
}

\author{
Moataz Hassanein ${ }^{1}$, Ahmed Abdel Hady ${ }^{2}$, Noha Helal ${ }^{2}$, Mohamed Eltalkawy ${ }^{1}$ and Tarek Aboushousha ${ }^{2 *}$ \\ ${ }^{1}$ Department of Gastroenterology and Hepatology, Theodor Bilharz Research Institute, Giza, Egypt \\ ${ }^{2}$ Department of Pathology, Theodor Bilharz Research Institute, Giza, Egypt
}

\begin{abstract}
Indications for liver biopsy technique were changed a lot over the recent few years. This was associated with dramatic revolution in viral diagnosis, viral vaccination and anti-viral therapy. This current work deals with a retrospective study of the prevalence of different hepatic lesions among liver biopsies received at Theodor Bilharz Research Institute within the periods from (1987 to 1989) compared to the period from (1996 to 1998) and from (2014 to 2016). It was found that the total number of liver biopsy specimens sent were not significantly changed during the three studied periods of time $(p>0.05)$. However, the number of liver biopsies was significantly and acutely decreased during the last two studied years $(2015$ and 2016$)(\mathrm{p}<0.05)$. A well reported difference was also noticed in the pattern of biopsied liver lesions, being mostly bilharzial hepatitis in the eighties and nineties, while viral hepatitis came over during the new century with a marked reduction in the histopathological diagnosis of bilharziasis. Our study showed a steady increase in the histopathological diagnosis of chronic viral hepatitis between the different periods studied. On the contrary histopathological diagnosis of bilharzial liver disease was declining with time, being only about $1.6 \%$ at the period of time from 2014 to 2016 . Diagnoses of autoimmune liver diseases, drug hepatitis, non-alcoholic fatty liver diseases (NAFD) and non-alcoholic steatohepatitis (NASH), were overcoming the diagnosis of bilharzial liver disease within recent years.
\end{abstract}

\section{Introduction}

Practiced since the late 19th century, liver biopsy - in combination with history and physical examination data - remains the powerful tool in the evaluation of the etiology and extent of liver disease as well as to determine management. Indications for liver biopsy include: secure the initial diagnosis, determine the degree of inflammatory activity (grading) and the extent of fibrosis (staging), evaluation of abnormal hepatic laboratory test results; suspected hepatic neoplasm, diagnosis of cholestatic liver disease, evaluation of infiltrative or granulomatous disease, monitoring of the progression of disease or of treatment efficacy as in cases of liver transplantation, evaluate unexplained jaundice or suspected drug reactions and to diagnose potentially comorbid conditions of the liver $[1,2]$.

Although liver biopsy is generally safe, however, sampling error, rare complications, and, occasionally, patient anxiety may occur. These factors have led to the development of noninvasive tests for hepatic fibrosis [3].

In recent years, advances in imaging techniques and development of reliable serological and virological tests, together with advances in drug therapy have greatly influenced the diagnosis and management of hepatic disease and as a consequence the indications for liver biopsy have changed. Serum based and radiologic non-invasive methods of assessing fibrosis can distinguish between limited and advanced hepatic fibrosis and diagnose cirrhosis [2]. below:

The prevalence of the commonest hepatic lesions in Egypt are listed

\section{Hepatitis C virus (HCV)}

HCV was discovered in 1989. Egypt is the country with the highest $\mathrm{HCV}$ prevalence in the world at that time; up to $20 \%$ of the general population is infected [4].
In 1999, The Egyptian Ministry of Health estimated the national prevalence rate of $\mathrm{HCV}$ positivity to be $25-30 \%$ of the population [5]. In 2008, the prevalence of HCV antibodies among the 15-59-year age group, was $14.7 \%$, with an estimated 6 million Egyptians had chronic HCV infection in 2008 [6]. Then, in 2015, the prevalence of HCV infection in Egypt was 10\% of Egyptians between 15 - 59 years of age, while 7\% are chronic active hepatitis C patients [7].

The development of highly efficacious oral direct-acting antivirals (DAAs) provides opportunities for reducing HCV disease burden and its onward transmission, with the potential for eliminating this virus as a public health concern [8]. Antiviral medicines can cure more than 95\% of persons with hepatitis $C$ infection, thereby reducing the risk of death from liver cancer and cirrhosis, but access to diagnosis and treatment is low [9].

\section{Hepatitis B virus (HBV)}

The prevalence of HBsAg in Egypt is of intermediate endemicity (2-8\%). Nearly 2-3 million Egyptians are chronic carriers of HBV. In early 1980s, the prevalence rate of HBsAg in the Egyptian population was moderately high (10.1\%); it was higher in the Upper Egypt (11.7\%) than the Lower Egypt (8.0\%) population and more frequent in young adults and males than females in both populations [10]. In 1992, Egypt started a program of universal immunization in infancy in accordance

${ }^{\star}$ Correspondence to: Tarek Aboushousha, Department of Gastroenterology and Hepatology, Theodor Bilharz Research Institute, Giza, Egypt, Tel 00201222186036; E-mail: t.aboushousha@tbri.gov.eg

Key words: Egypt, Liver biopsy, chronic hepatitis, Bilharziasis, autoimmune hepatitis, Non-alcoholic steatohepatitis, HCC

Received: May 05, 2018; Accepted: May 16, 2018; Published: May 19, 2018 
with the WHO recommendations. In 2017, a recent cross-sectional analysis study conducted to detect prevalence of HBV among Egyptians aged $15-59$ years, it reported prevalence rate of $1.4 \%$ with low rates of HBV-HCV co-infection $(0.06 \%)$ despite exceptionally high prevalence of HCV nationwide [11].

In hepatitis B infection, the demonstration of a significant degree of fibrosis and/or inflammation in liver biopsy is a decisive factor both for the indication for treatment and for the choice of an antiviral treatment strategy [12].

\section{Schistosomiasis (Bilharziasis)}

World Health Organization (WHO) considers schistosomiasis as the second only to malaria in socioeconomic importance worldwide and the third more frequent parasitic disease in public health importance [13]. The history of schistosomiasis in Egypt is longstanding for over 5000 years, with reports of Schistosoma eggs in ancient mummies [14].

In the early 1920s; reports from the Egyptian government indicate $70-80 \%$ infection rates, with the only treatment was the intravenous tartar emetic $[15,16]$.

By 1980, a new compound called praziquantel was used and found to have up to $90 \%$ efficacy in eradicating infection after only one dose. Armed with this new agent, the United States Agency for International Development and the Ministry of Health and Population (MOHP) of Egypt collaborated to design and implement the Schistosomiasis Research Project (SRP) to provide Egypt with better tools to control schistosomiasis [17]. In 1997, there was another program, the National Schistosomiasis Control Project (NSCP) that starts mass chemotherapy against schistosomiasis in schools and high-prevalence villages. With success of the NSCP, the threshold for treatment was lowered from a prevalence of $20 \%$ to $10 \%$ in 1999 (paper 1), and by 2010 the prevalence was estimated to have dropped to $<3 \%[18]$.

Liver biopsy identifies schistosomal granulomatous reaction that involves lymphocytes, macrophages, eosinophils, collagen deposition and fibrosis around trapped schistosomal eggs.

\section{Co-Infection of Schistosomiasis with Viral Hepatitis}

Co-infection of Schistosomiasis with viral hepatitis, either HBV or $\mathrm{HCV}$ is very common since the regions with a high prevalence of schistosomiasis usually have a high endemicity of chronic viral hepatitis as well. As a result of extensive schistosomiasis control programs with intravenous tartar emetic 20-50 years ago, that was unfortunately leading to spread of hepatitis B and C through re-use of needles [5]. In addition, this co-infection can also produce a unique clinical, virologic and histologic pattern manifested by viral persistence with high HCV RNA titers, higher necro-inflammatory and fibrosis scores in liver biopsy specimens in addition to poor response to interferon therapy, and accelerated progression of hepatic fibrosis [19].

\section{Non-Alcoholic Fatty Liver Disease (NAFLD)}

NAFLD is the most common chronic liver disease worldwide, with a global prevalence estimated at $25-35 \%$ of the world's population, but with geographical variability; the highest prevalence has been noted amongst western countries, meanwhile, prevalence of NAFLD is growing in the developing world [20].

In Egypt, NAFLD is a silent disease influencing the Egyptian population, with risk increased with advanced age [21]. NAFLD is closely associated with obesity, type 2 diabetes, dyslipidemia and other metabolic risk factors, and is commonly regarded as the hepatic component of metabolic syndrome [20].

The distinction between NAFL and NASH is hard to draw from laboratory tests alone. Liver biopsy enables accurate diagnosis of both lesions; NAFL is characterized by steatosis of the liver, involving greater than $5 \%$ of parenchyma, with no evidence of hepatocyte injury, whereas, NASH is defined as necroinflammatory process whereby the liver cells become injured in a background of steatosis [22].

\section{Autoimmune Hepatitis (AIH)}

$\mathrm{AIH}$ is a progressive inflammatory liver disorder mainly affecting females and is a common cause of acute and chronic hepatitis which leads to cirrhosis and end-stage liver disease if left untreated with apparently good survival with early diagnosis and treatment [23,24]. Liver biopsy should be performed to secure the initial diagnosis and for grading and staging, as well as for therapeutic monitoring. Liver biopsy is also necessary prior to discontinuation of immunosuppressive therapy; since the presence of histological piecemeal necrotic lesions is associated with almost constant recurrence [25]. Interface hepatitis, lymphocytic/lymphoplasmocytic infiltrates in portal tracts and extending into the lobule, emperipolesis (active penetration by one cell into and through a larger cell), and hepatic rosette formation were regarded as typical for the diagnosis of AIH [26].

\section{Drug-Induced Liver Injury (DILI)}

Drugs are an important cause of liver injury. More than 900 drugs, toxins, and herbs have been reported to cause liver injury, and drugs account for $20-40 \%$ of all instances of fulminant hepatic failure. Approximately $75 \%$ of the idiosyncratic drug reactions result in liver transplantation or death. Drug-induced hepatic injury is the most common reason cited for withdrawal of an approved drug. In general, adults are at higher risk for DILI than children. Females may be more susceptible to DILI than males [27].

Cholestatic Liver Diseases including: a) Primary Biliary Cholangitis (primary biliary cirrhosis (PBC) in which liver biopsy is not useful for diagnosis of $\mathrm{PBC}$ but is very useful for assessing the activity and extent of fibrotic lesions $[28,29]$. b) Primary Sclerosing Cholangitis (PSC) that can also be an indication for liver biopsy, however other non-invasive techniques can be diagnostic [30].

Focal Hepatic Lesions; that may be either a) Solitary Lesion in a Cirrhotic Liver, b) Solitary Lesion in a Non-Cirrhotic Liver or c) Livercell adenoma [1].

\section{Hepatocellular Carcinoma (HCC)}

HCC is a common malignancy throughout the world, with an estimated incidence of up to 1,000,000 new cases per year. In Egypt, $\mathrm{HCC}$ is a major health problem and its incidence is increasing being related to high incidence of HCV [31]. HCC constitutes $70.48 \%$ of all liver tumors among Egyptians and represents the main complication of cirrhosis with about $21 \%$ of cirrhotic patients at risk of developing HCC [32,33].

\section{Material and methods}

This study included 669 liver biopsies received at the pathology department of Theodor Bilharz Research Institute. A histopathology request was received with each biopsy, containing the patient personal data, clinical diagnosis, laboratory investigations and radiological findings. 
Routine histopathological processing and examination was done by staining of paraffin sections with haematoxylin/eosin and Masson's trichrome stains for grading and staging of hepatitis activity and scoring of fibrosis as well as diagnosis and grading of malignancy. Other stains were also used on need like silver stain for reticulin fibers, Perl's Prussian blue stain for iron detection and orcein stain for copper.

Grade of hepatitis activity and stage of fibrosis were calculated using METAVIR scoring system [34].

Grade of hepatitis activity based on amount of inflammation:

A1: mild activity, A2: moderate activity, A3: severe activity.

Stage of fibrosis; representing amount of fibrosis or scarring:

F1: portal fibrosis without septa, F2: portal fibrosis with few septa, F3: numerous septa without cirrhosis, F4: cirrhosis.

In our study, for simplicity, we have grouped A1 and A2 as low hepatitis activity and A3 as high hepatitis activity. We have also grouped F1, F2 and F3 as fibrosis and F4 as cirrhosis.

HCC grade was done according to the WHO classification of tumors of the liver and intrahepatic bile ducts into [35]:

Grade 1: (Well differentiated)

Grade 2: (Moderately differentiated)

Grade 3: (Poorly differentiated)

\section{Statistical Analysis}

The statistical analysis of the results was done with analysis of variance (ANOVA) to compare different groups. Results were given as mean \pm SD. Distribution of negative and positive cases was studied with cross tables (Chi square-test). Statistical analysis was done using (SPSS software program, version 20). In all tests, a $\mathrm{P}<0.05$ was considered to be of statistical significance.

\section{Results}

Our study showed a steady increase in the histopathological diagnosis of chronic viral hepatitis between the different periods studied. On the contrary histopathological diagnosis of bilharzial liver disease was declining with time, being only about $1.6 \%$ at the period of time from 2014 to 2016. (Table $1 \&$ Histogram 1)

There is continuous decrease in the number of received liver biopsies at the pathology department of Theodor Bilharz Research Institute, during the last three years studied (from 2014 to 2016). The difference was statistically significant $(\mathrm{p}<0.05)$. (Table $2 \&$ Histogram 2$)$

Within recent years (from 2014 to 2016), there was a continuous decrease in the number of liver biopsies diagnosed as chronic hepatitis (B, C, mixed or others), while there was a non-significant decrease in the percentage of histopathological diagnosis of these cases. Bilharzial liver diseases were occasionally diagnosed nowadays. (Table $3 \&$ Histogram 3)

The table below showed a list of liver biopsies' diagnoses during the last three years (from 2014 to 2016), with the vast majority of liver biopsies were diagnosed as chronic hepatitis C (68.75\%). Diagnoses of autoimmune liver diseases, drug hepatitis, non-alcoholic fatty liver diseases (NAFD) and non-alcoholic steatohepatitis (NASH), were overcoming the diagnosis of Schistosomal liver disease within recent years.(Table 4).

The vast majority of the received liver biopsies in the year interval from 2014 to 2016 were requested for serologically HCV positive chronic hepatitis cases (67.91\%). Jaundice and focal hepatic lesions represented the second main clinical criteria reported in the request

Table 1. Differences in liver biopsy diagnoses over 3 decades

\begin{tabular}{|c|c|c|c|c|}
\hline Year & $\begin{array}{c}\text { Chronic viral hepatitis } \\
\mathbf{n}(\mathbf{\%})\end{array}$ & $\begin{array}{c}\text { Bilharzial } \\
\mathbf{n}(\mathbf{\%})\end{array}$ & $\begin{array}{c}\text { Mixed Bilharzial and Viral } \\
\text { hepatitis } \\
\text { n (\%) }\end{array}$ & $\begin{array}{c}\text { Chronic hepatitis } \\
\text { (others) } \\
\text { n (\%) }\end{array}$ \\
\hline $\mathbf{1 9 8 7 - 1 9 8 9}$ & $99(35.6)$ & $98(36)$ & $6(2.16)$ & $73(26.3)$ \\
\hline $\mathbf{1 9 9 6 - 1 9 9 8}$ & $109(53)$ & $38(18.5)$ & $30(14.6)$ & $28(13.5)$ \\
\hline $\mathbf{2 0 1 4 - 2 0 1 6}$ & $173(89.9)$ & $3(1.6)$ & -- & $12(6.4)$ \\
\hline Total & 381 & 139 & 36 & 205 \\
\hline
\end{tabular}

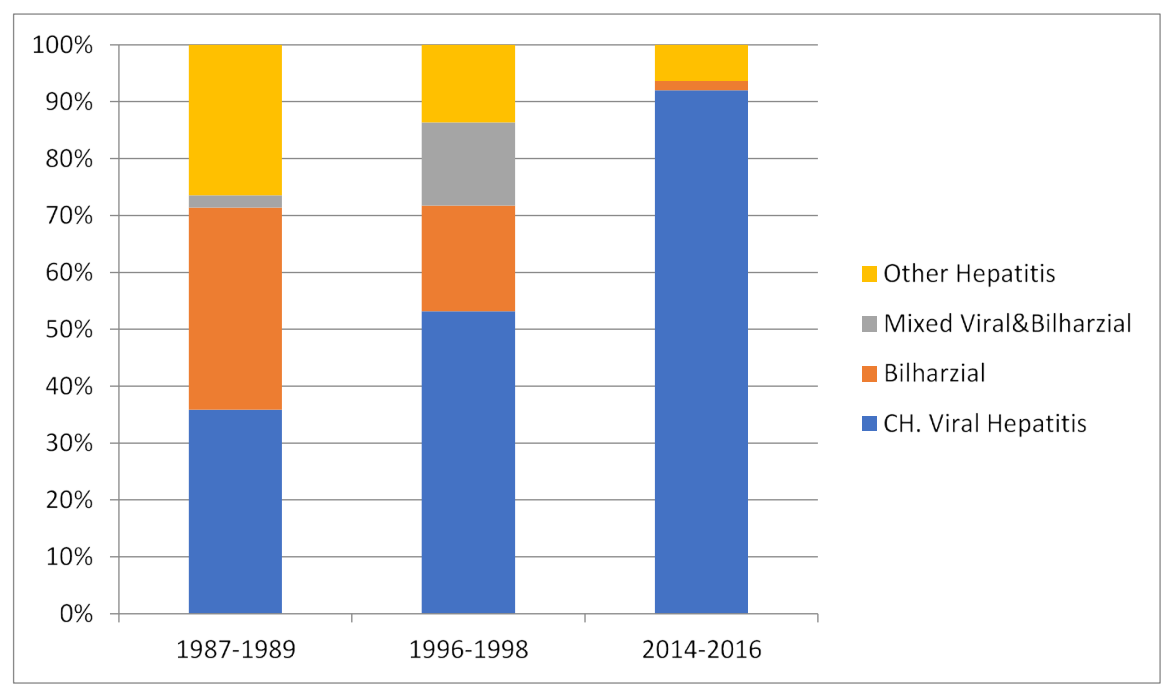

Histogram 1. Differences in liver biopsy diagnoses over 3 decades 
Table 2. Changes in number of liver biopsies over the years (2014 to 2016)

\begin{tabular}{|c|c|}
\hline Year & Number of cases \\
\hline 2014 & 130 \\
\hline 2015 & 69 \\
\hline 2016 & 41 \\
\hline Total number & 240 \\
\hline
\end{tabular}

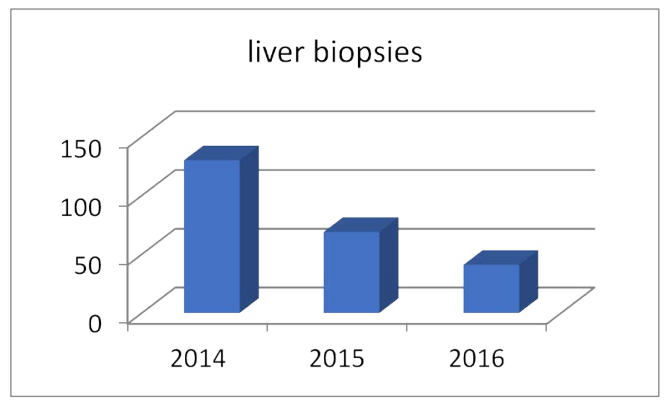

Histogram 2. Changes in number of liver biopsies over the years (2014 to 2016)

Table 3. Changes in liver biopsy diagnoses over recent years

\begin{tabular}{|c|c|c|c|c|c|c|}
\hline Year & $\begin{array}{c}\text { Chronic C hepatitis } \\
\text { n (\%) }\end{array}$ & $\begin{array}{c}\text { Chronic B } \\
\text { hepatitis n (\%) }\end{array}$ & $\begin{array}{c}\text { Mixed B\&C } \\
\text { n (\%) }\end{array}$ & Schistosomal n (\%) & $\begin{array}{l}\text { Chronic Hepatitis } \\
\text { (other) n (\%) }\end{array}$ & Total n (\%) \\
\hline 2014 & $100(88.5)$ & $2(1.8)$ & $1(0.9)$ & $2(1.8)$ & $8(7.08)$ & 113 \\
\hline 2015 & $43(87.8)$ & $1(2.04)$ & $1(2.04)$ & $1(2.04)$ & $2(4.08)$ & 49 \\
\hline 2016 & $22(84.6)$ & $2(7.7)$ & $0(0)$ & $0(0.0)$ & $2(7.7)$ & 26 \\
\hline 2014-2016 & $165(89.9)$ & $5(2.7)$ & $3(1.6)$ & $3(1.6)$ & $12(7.7)$ & 188 \\
\hline
\end{tabular}

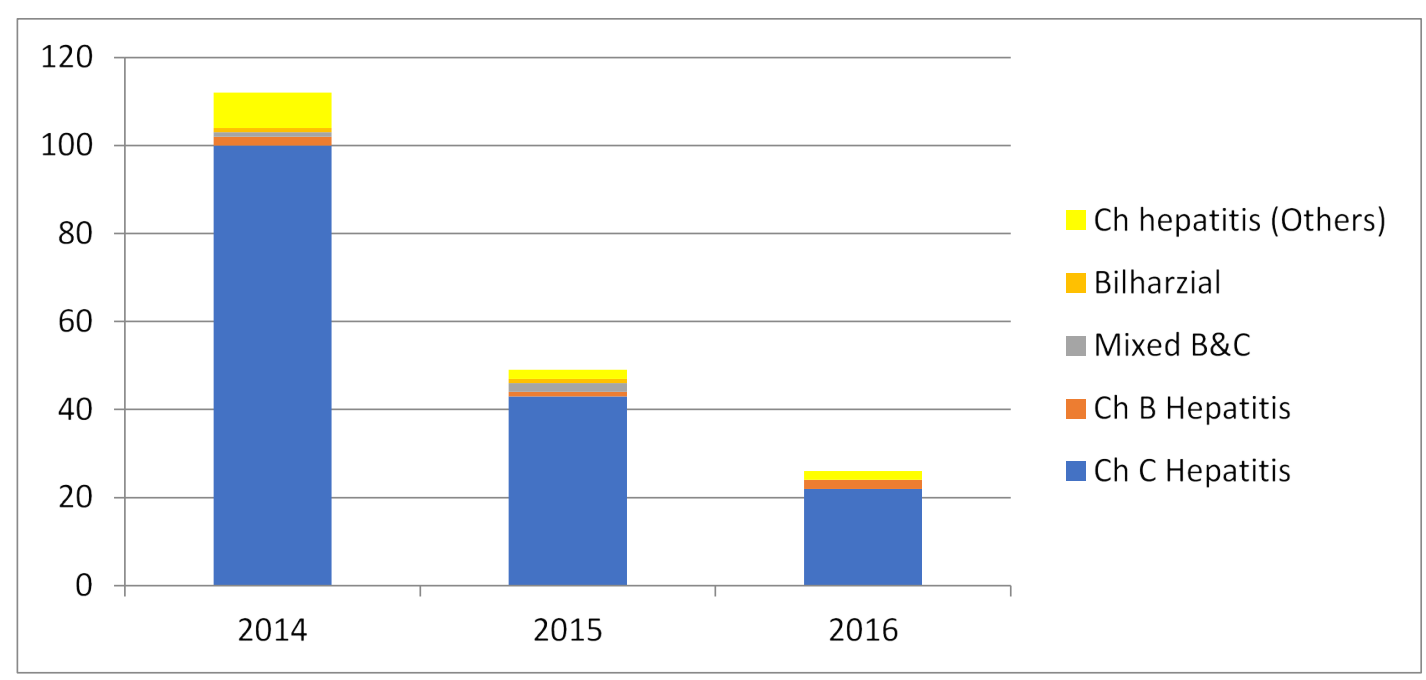

Histogram 3. Changes in liver biopsy diagnoses over recent years

sent for histopathological examination of liver biopsies $(8.75 \%$ and $6.25 \%$ respectively). (Table 5)

\section{Discussion}

Liver biopsy and histology remain the gold-standard method providing valuable information regarding disease etiology and activity as well as in diagnosing fibrosis, but liver biopsy is not useful when diagnosis of cirrhosis is obvious [35]. Also, while abdominal ultrasonography is satisfactory for assessing the existence of steatosis, liver biopsy is needed in order to evaluate the existence of steatohepatitis, iron overload or alcoholic liver disease associated with hepatitis C. Such lesions are associated with more rapid fibrosis progression and a less favourable response to treatment [2].
In this study, we found an increase in the histopathological diagnosis of chronic viral hepatitis between the three examined time intervals, indicating that liver biopsy remains an essential method for assessing the degree of fibrosis and necro-inflammation, information that is frequently integral in determining the need for initiating antiviral treatment. Endemicity of HCV in Egypt throughout years accounts the major indication for liver biopsy. It was mainly attributed to patients who received anti-schistosomal injections in the $1950 \mathrm{~s}$ and 1960s and then manifest HCV disease 20 years later, in addition, available lines of treatment were not as efficient in complete control of the disease. In the start of the 1990s, treatment with interferon alpha (INF- $\alpha$ ) monotherapy was considered to be the gold standard for HCV treatment, however cure rate was of less than $20 \%$ in Egyptian patients 


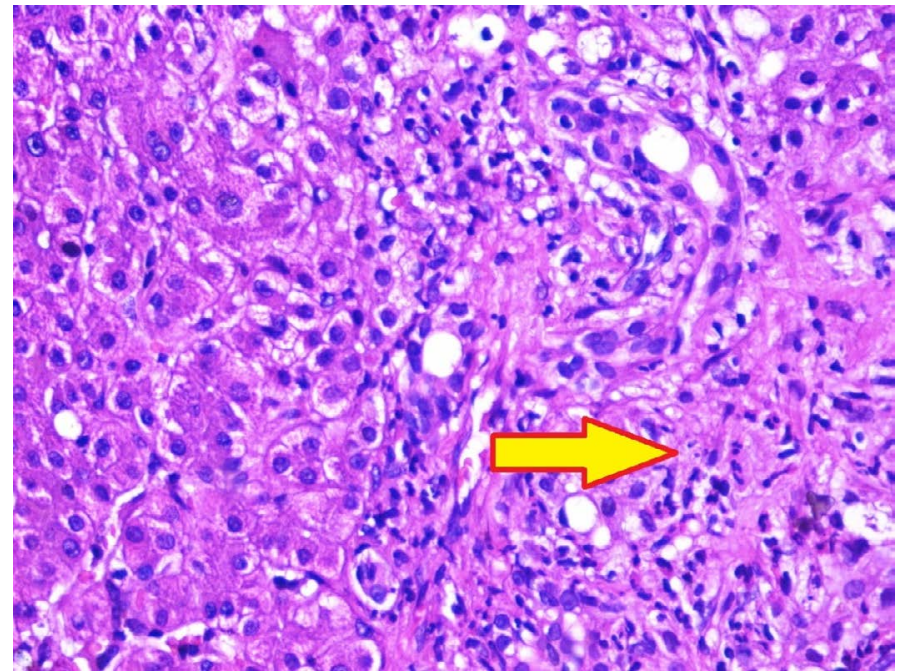

Figure 1. A case of secondary (ascending) cholangitis with infiltration of the portal tract around bile ductules by many neutrophils (arrow) (H\&E stain, X400)

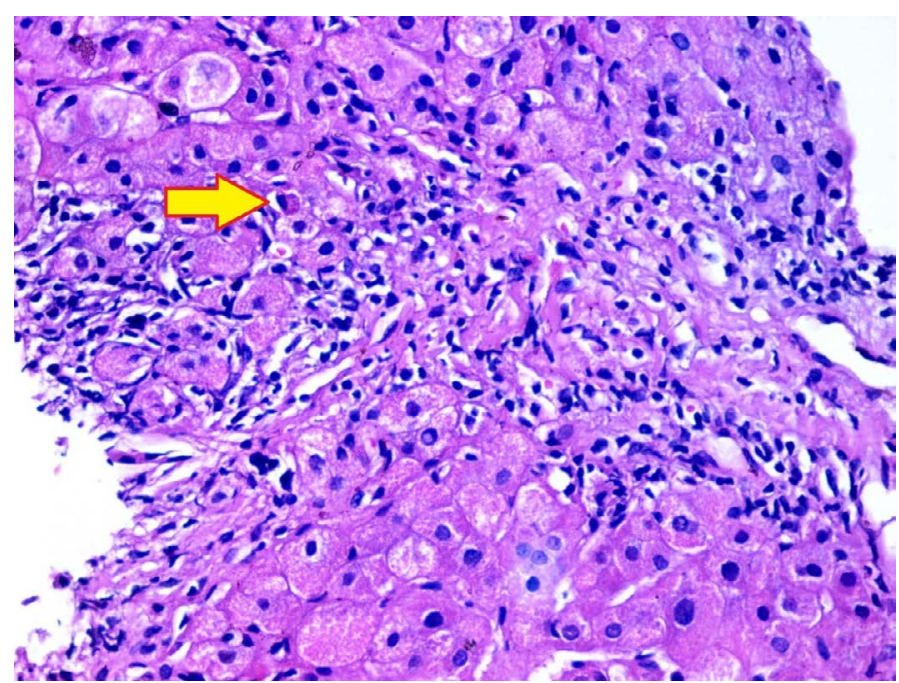

Figure 2. A case of autoimmune hepatitis, showing infiltration by mononuclear cells including scattered plasma cells (arrow) (H\&E stain,X400)

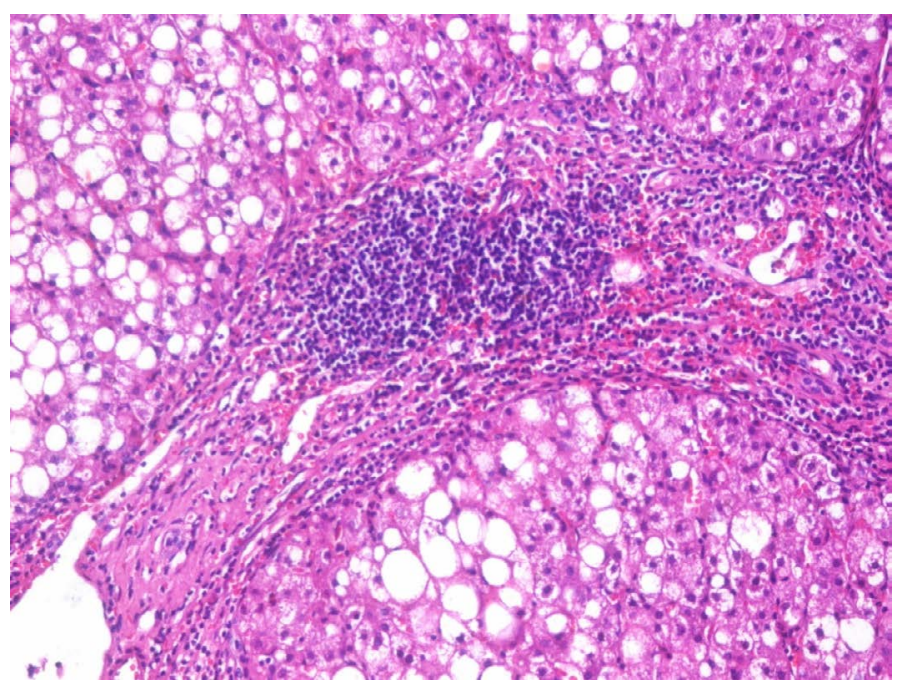

Figure 3. A case of chronic hepatitis $\mathrm{C}$, with infiltration of the portal tract by aggregates of lymphocytes and widespread hepatocytic macrovesicular steatosis. (H\&E stain,X400)

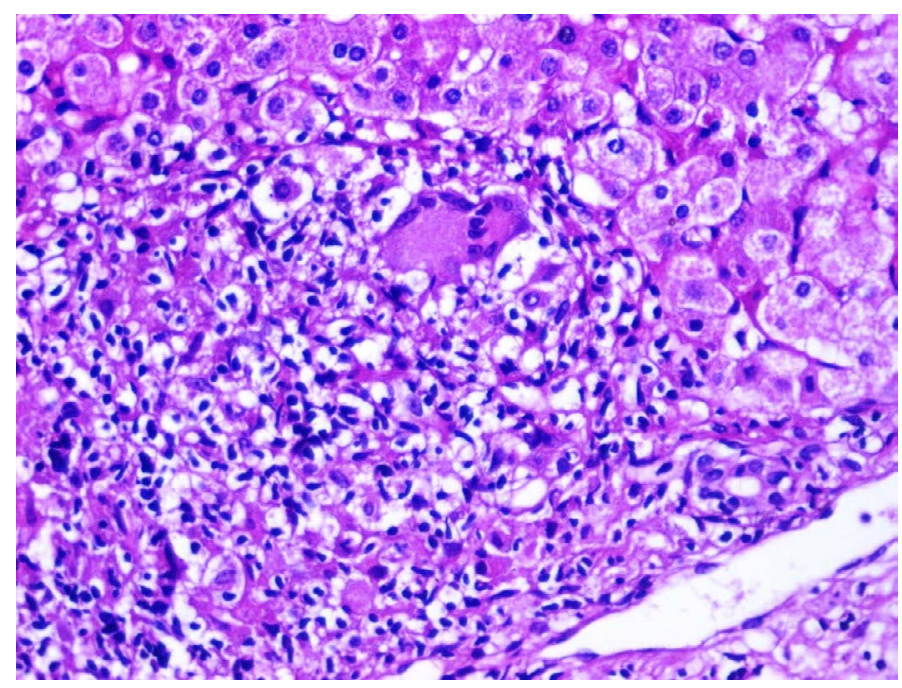

Figure 4. A case of granulomatous hepatitis with infiltration of the portal tract by mononuclear inflammatory cells, epithelioid cells and few multinucleated giant cells (H\&E stain,X400)

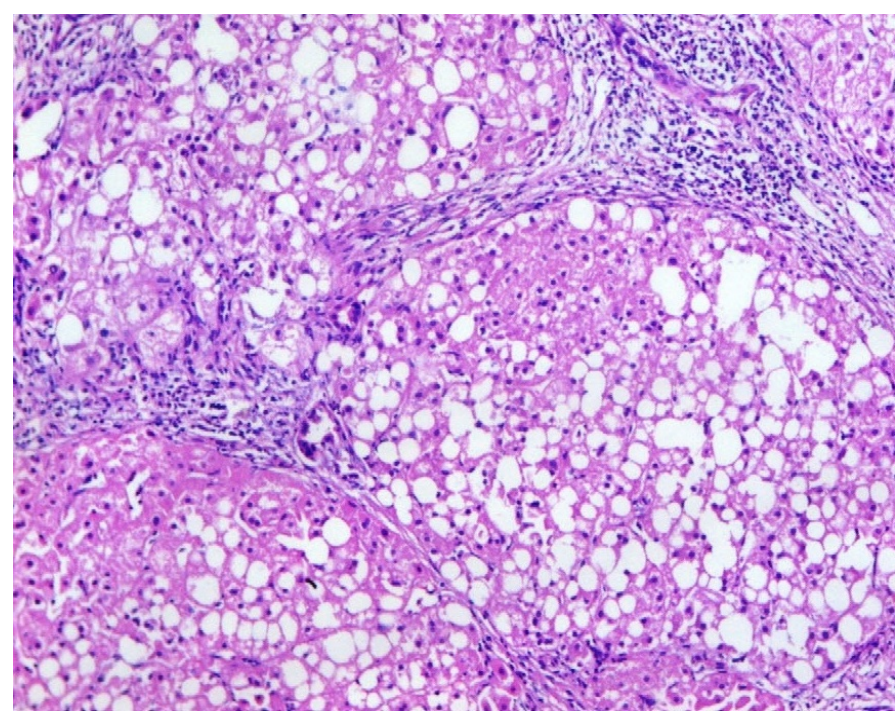

Figure 5. A case of steatohepatitis, merging into cirrhosis (H\&E stain,X200)

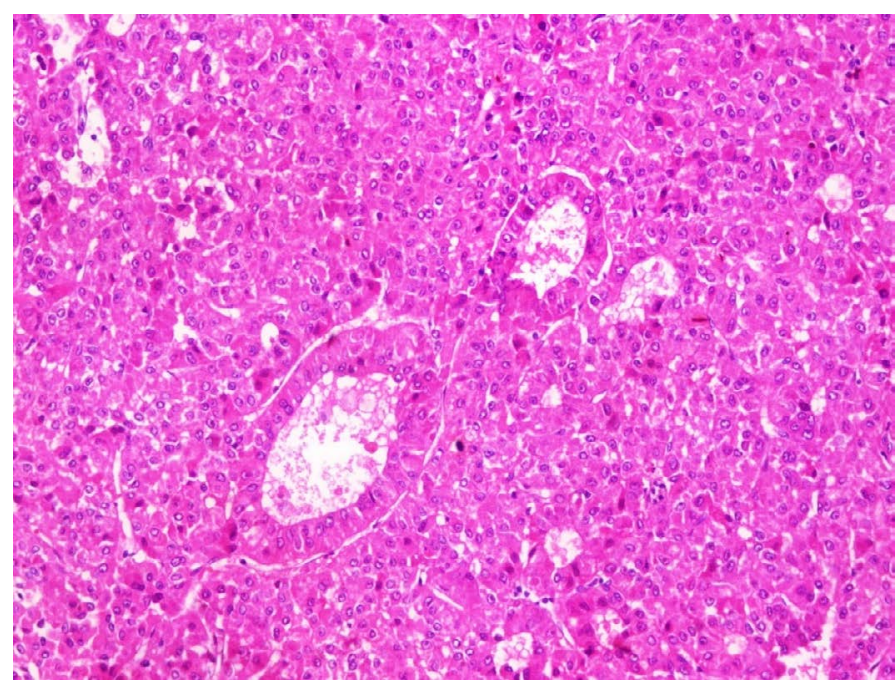

Figure 6. A case of moderately differentiated hepatocellular carcinoma with focal acinar pattern (H\&E stain,X200) 
Table 4. List of histopathological diagnoses during the years (2014-2016)

\begin{tabular}{|l|l|}
\hline Histopathological diagnosis (2014-2016) & Number (\%) \\
\hline Abscess & $7(2.9 \%)$ \\
\hline Autoimmune Liver Disease & $12(5 \%)$ \\
\hline Schistosomal & $3(1.25 \%)$ \\
\hline Chronic hepatitis (others) & $12(5 \%)$ \\
\hline Chronic hepatitis B & $5(2.08 \%)$ \\
\hline Chronic hepatitis C & $165(68.75 \%)$ \\
\hline Chronic hepatitis B\&C & $2(0.8 \%)$ \\
\hline Cholangitis & $4(1.6 \%)$ \\
\hline Cirrhosis & $1(0.4 \%)$ \\
\hline Drug hepatitis & $5(2.08 \%)$ \\
\hline Dysplasia & $1(0.4 \%)$ \\
\hline Granuloma & $1(0.4 \%)$ \\
\hline HCC & $4(1.6 \%)$ \\
\hline Hydatid & $2(0.8 \%)$ \\
\hline Metastasis & $4(1.6 \%)$ \\
\hline NAFD & $9(3.75 \%)$ \\
\hline NASH & $3(1.25 \%)$ \\
\hline Total & $240(100 \%)$ \\
\hline
\end{tabular}

Table 5. Main representing clinical picture (as per histopathological request)

\begin{tabular}{|l|l|l|}
\hline Main representing clinical picture (as per histopathological request) & Total \\
\hline & Acute hepatitis symptoms & $5(2.08 \%)$ \\
\hline & Chronic hepatitis symptoms & $9(3.75 \%)$ \\
\hline & Known as a Donor liver & $6(2.50 \%)$ \\
\hline & Known as an Explant liver & $1(0.4 \%)$ \\
\hline & Serologically diagnosed HBV & $6(2.50 \%)$ \\
\hline CLINICAL & Serologically diagnosed HCV & $163(67.91 \%)$ \\
\hline & Focal Hepatic Lesion & $15(6.25 \%)$ \\
\hline & Jaundice & $21(8.75 \%)$ \\
\hline & Known metastatic lesion & $7(2.9 \%)$ \\
\hline & Pain & $6(2.50 \%)$ \\
\hline Total & Weight loss & $1(0.4 \%)$ \\
\hline & & $240(100 \%)$ \\
\hline
\end{tabular}

[36]. As approximately $90 \%$ of patients belong to a single subtype, genotype $4 \mathrm{a}$, which responds less successfully to interferon therapy than other subtypes [37]. In 1999, combined treatment of pegylated interferon (PEG-IFN) alpha and ribavirin markedly improves treatment outcomes, resulting in a sustained virologic response (SVR) in $44 \%-69 \%$ of cases [38].

However, trend in indications for liver biopsy for hepatitis C gradually decreased over the last studied three years (2014-2016) in our institution, this trend being related to the remarkable progress in the treatment of HCV that makes liver biopsy unnecessary in a large number of patients who previously were treated based on the stage of disease as determined by biopsy [39]. Starting treatment with the new direct-acting antiviral (DAA) drugs that were introduced into Egypt in late 2014 has reduced treatment duration to12-24 weeks with cure rates of $85-95 \%$ across all patient populations, this leads to decrease in HCV prevalence from $14.7 \%$ in 2008 to $10 \%$ in 2015 , with the goal of achieving a national chronic infection prevalence of $<2 \%$ by 2025 [42]. Treatment may show a larger impact in the near future as it is expected that emphasis will be put on an upscale of treatment of infected persons to prevent long-term complications [43].

Furthermore, assessment of liver fibrosis in HCV patients can be performed through several noninvasive methods, including radiologic and serum biomarker tests and this reduces the need for liver biopsy. Radiologic methods are ultrasound elastography (FibroScan) and magnetic resonance elastography (MRE). Serum tests are HepaScore, FibroSure, FibroMeter, the FIB- 4 index, and the European Liver Fibrosis test [44]. These tests assess blood levels of hyaluronic acid and other chemicals to help estimate the degree of liver inflammation and fibrosis. Also, Fibroscan is useful for confirming or ruling out the presence of cirrhosis and can evaluate patients with portal hypertension, to assess recurrence of disease following liver transplantation, and to predict survival in patients with liver disease $[45,46]$.

In our study, the number of liver biopsies diagnosed as chronic hepatitis B is very low, this is attributed to implement of HBV vaccination in Egypt since 1992, which is considered the most effective measure to prevent HBV infections, mainly targeting newborns followed by previously unvaccinated infants, children and adolescents under the age of 15 years-old, and high-risk population members (e.g., health care workers, workers in nurseries and kindergartens, patients receiving organ transplantation, patients receiving frequent blood transfusions or blood products, immunocompromised patients, household contacts with an HBsAg-positive person, etc. [47].

Furthermore, antiviral therapy for chronic active hepatitis B infection can often be initiated without a liver biopsy as the benefit of treatment extends across all stages of fibrosis [38].

In our institution, the total number of liver biopsies steadily decreased over the examined time periods, due to progressive decrease in liver biopsies performed for lesions other than chronic viral hepatitis. As there was progressive decrease in liver biopsies performed for Schistosomal disease, due to successful control of Schistosomiasis that reduces both prevalence and morbidity of disease over the past 40 years in Egypt through the implementation of several control projects which adopted the same strategy recommended by the WHO [48].

Last project was carried out on 2011 aimed at targeting more than 6 million people to be treated over 5 years through involving snail control and other environmental interventions such as access to safe water, sanitation and health education in addition to preventive chemotherapy campaigns [49].

In addition, there was also progressive decrease in liver biopsies performed for cases of other causes of chronic hepatitis due to performance of non-invasive techniques for diagnosis, as in cases of autoimmune hepatitis as its diagnosis can be achieved serologically by high levels of transaminases and immunoglobulin $\mathrm{G}$, and the presence of autoantibodies; AIH type 1 are positive for antinuclear antibody (ANA) and/or anti-smooth muscle antibody (ASM), AIH type 2 are positive for anti-liver-kidney-microsomal antibody type1 (AntiLKM-1) [50]. In fatty liver disease ultrasound detects moderate-tosevere steatosis ( $>20 \%$ fat) and ultrasound elastography (Fibroscan) also permits quantification of hepatic steatosis [51]. Steatosis FibroMeter and Fibromax can provide evidence of the existence of fibrosis and can predict the existence of NASH $[52,53]$. In Primary biliary cholangitis, although liver biopsy is recommended, this disease can be diagnosed on serological grounds alone by the demonstration of a high titer of anti-mitochondrial antibodies (AMA) specific for the E2 subunit of pyruvate dehydrogenase (AMA-M2) [54]. Also, FibroScan can assess the presence or absence of cirrhosis [55]. In Primary sclerosing cholangitis, the characteristic sclerosing changes in the biliary pathways can be sought by endoscopic retrograde cholangiopancreaticography (ERCP) or magnetic resonance cholangiopancreaticography (MRCP) and less often with percutaneous transhepatic cholangiography [28]. In cases of focal hepatic lesions (single or multiple); ultrasonography, computerized tomography (CT), and/or magnetic resonance imaging 
(MRI) are generally conclusive, however, no biopsy is needed when the lesion is clearly a metastasis of a known primary tumor [1]. In HCC, initial assessment has done be by spiral computed tomography, magnetic resonance imaging with contrast enhancement or angiography with lipiodol injection as well as by measurement of serum alpha fetoprotein. Liver biopsy is rarely required for diagnosis and biopsy of potentially operable lesions should be avoided [56].

\section{Conclusion}

In this single-center retrospective study, our data reflects recent trends in the indications for liver biopsy in different lesions of chronic hepatitis diagnosed at Department of Pathology, Theodor Bilharz Research Institute during the last three decades. These changes may be related to usage of other serological and radiological techniques in determining etiology of disease and evaluation of fibrosis; particularly in the context of autoimmune liver diseases and cholestatic liver diseases, as well as the decreasing role of liver biopsy for HCV management. The difference could be also attributed to the changes in the prevalence of variable insults affecting the liver in Egyptian patients.

\section{Acknowledgment}

I declare no conflict of interest.

\section{References}

1. Tannapfel A, Dienes HP, Lohse AW (2012) The Indications for Liver Biopsy. Dtsch Arztebl Int 109: 477-483.

2. Cadranel JF, Nousbaum JB. Current Trends in Liver Biopsy Indications for Chronic Liver Diseases, Liver Biopsy Nobumi Tagaya. IntechOpen

3. Non-Invasive Methods for Diagnosis and Monitoring of Liver Fibrosis in Patients with Chronic Hepatitis B and C (2015) A Review of Diagnostic Accuracy, Clinical Effectiveness, Cost-Effectiveness and Guidelines [Internet]. Ottawa (ON): Canadian Agency for Drugs and Technologies in Health.

4. Miller FD, Abu-Raddad LJ (2010) Evidence of intense ongoing endemic transmission of hepatitis C virus in Egypt. PNAS 107: 14757-14762.

5. Frank C, Mohamed MK, Strickland GT, Lavanchy D, Arthur RR (2000) The role of parenteral antischistosomal therapy in the spread of hepatitis C in Egypt. Lancet 11: 887-891. [Crossref]

6. El-Zanaty F, Way A (2009) Egypt Demographic and Health Survey 2008. Cairo, Egypt: Ministry of Health, El-Zanaty and Associates, and Macro International.

7. (2015) Ministry of Health and Population [Egypt], El-Zanaty and Associates [Egypt], and ICF International. Egypt Health Issues Survey 2015. Ministry of Health and Population and ICF International.

8. Stanaway JD, Flaxman AD, Naghavi M, Fitzmaurice C, Vos T (2016) The global burden of viral hepatitis from 1990 to 2013: findings from the Global Burden of Disease Study 2013 Lancet 388: 1081-1088. [Crossref]

9. World Health Organization. Hepatitis $\mathrm{C}$ virus fact sheet.

10. Sherif MM, Abou-Aita BA, Abou-Elew MH, El-Kafrawi O (1985) Hepatitis B virus infection in upper and lower Egypt. J Med Virol 15:129-135. [Crossref]

11. Ismail SA, Cuadros DF, Benova L (2017) Hepatitis B in Egypt: A cross-sectional analysis of prevalence and risk factors for active infection from a nationwide survey. Liver Int 37:1814-1822. [Crossref]

12. Cornberg M, Protzer U, Petersen J, Wedemeyer H, Berg T (2011) Prophylaxis, diagnosisand therapy of hepatitis B virus infection - the German guideline. $Z$ Gastroenterol 49: 871-930. [Crossref]

13. Sarvel AK, Oliveira AA, Silva AR, Lima AC, Katz N (2011) Evaluation of a 25-yearprogram for the control of schistosomiasis mansoni in an endemic area in Brazil. PLoS Negl Trop Dis 5: e990. [Crossref]

14. David AR (2000) 5000 years of schistosomiasis in Egypt. Chungara 32: 133-135.

15. Barlow CH (1930) First Quarterly Report in Rockefeller Foundation Archive, Barlow Papers Series Box 1 Folder 3. Rockefeller Foundation.
16. Khalil M (1924) The History and progress of anti ankylostomiasis and anti-bilharziasis work. In Egypt, Part III Resumption Campaign 1919, Report of Public Health Laboratories in Government Records, Cairo.

17. Salem S, Mitchell RE, El-Alim El-Dorey A, Smith JA, Barocas DA (2011) Successfu control of schistosomiasis and the changing epidemiology of bladder cancer in Egypt. BJU Int 107: 206-211. [Crossref]

18. Rollinson D, Knopp S, Levitz S, Stothard JR, Tchuem Tchuenté LA, (2013) Time to set the agenda for schistosomiasis elimination. Acta Trop 128: 423-440. [Crossref]

19. Kamal SM, Turner B, He Q, Rasenack J, Bianchi L (2006) Progression of fibrosis in hepatitis $\mathrm{C}$ with and without schistosomiasis: correlation with serum markers of fibrosis. Hepatology 43: 771-779. [Crossref]

20. Younossi ZM, Koenig AB, Abdelatif D, Fazel Y, Henry L (2016) Global epidemiology of nonalcoholic fatty liver disease-Meta-analytic assessment of prevalence, incidence, and outcomes. Hepatology 64: 73-84. [Crossref]

21. Borai IH, Shaker Y, Kamal MM, Ezzat WM, Ashour E (2017) Evaluation of Biomarkers in Egyptian Patients with Different Grades of Nonalcoholic Fatty Liver Disease. J Clin Transl Hepatol 5: 109-118. [Crossref]

22. Kanwar P, Kowdley KV (2016) The Metabolic Syndrome and Its Influence on Nonalcoholic Steatohepatitis. Clin Liver Dis 20: 225-243. [Crossref]

23. Manns M, Strassburg C (2001) Autoimmune hepatitis: Clinical challenges. Gastroenterol 120: 1502-1517. [Crossref]

24. Czaja AJ (2016) Diagnosis and management of autoimmune hepatitis: current status and future directions. Gut Liver 10: 177-203. [Crossref]

25. Verma S, Gunuwan B, Mendler M, Govindarajan S, Redeker A (2004) Factors predicting relapse and poor outcome in type I autoimmune hepatitis: role of cirrhosis development, patterns of transaminases during remission and plasma cell activity in the liver biopsy. Am J gastroenterology 99: 1510-1516. [Crossref]

26. Gatselis NK, Zachou K, Koukoulis GK, Dalekos GN (2015) Autoimmune hepatitis, one disease with many faces: Etiopathogenetic, clinico-laboratory and histological characteristics. WJG 2015 21: 60-83. [Crossref]

27. Mehta N, Pinsky MR (2016) Drug-Induced Hepatotoxicity. Medscape Updated

28. Weinmann A, Sattler T, Unold HP, Grambihler A, Teufel A (2014) Predictive Scores in Primary Biliary Cirrhosis: A Retrospective Single Center Analysis of 204 Patients". $J$ Clin Gastroenterology. 49: 438-447. [Crossref]

29. EASL Clinical Practice Guidelines: management of cholestatic liver diseases (2009) Journal of hepatology. 51: 237-267. [Crossref]

30. Lewin M, Vilgrain V, Ozenne V, Lemoine M, Wendum D (2009) Prevalence of sclerosing cholangitis in adults with autoimmune hepatitis: a prospective magnetic resonance imaging and histological study. Hepatol 50: 528-537. [Crossref]

31. Shaker MK, Abdella HM, Khalifa MO, El Dorry AK (2013) Epidemiologica characteristics of hepatocellular carcinoma in Egypt: a retrospective analysis of 1313 cases. Liver Int 33: 1601-1606. [Crossref]

32. Mokhtar N, Gouda I, Adel I (2007) Cancer pathology registry 2003-2004 and time trend analysis. In: Mokhtar N, Gouda I, Adel I, eds. Malignant digestive system tumors. Cairo: Elsheraa Press 55-67.

33. Abdel-Atti E (2015) HCC Burden in Egypt. Gastroenterol Hepatol 2: 00-045.

34. Poynard T, Ratziu, V, Benmano Y, Di Martino V, Bedossa P (2000) Fibrosis in Patients with Hepatitis C: Detection and Significance: Detection and Significance. Semin Liver Dis 20: 47-55. [Crossref]

35. Bosman FT, Carneiro F, Hruban RH, Theise ND (2010) Hepatocellular carcinoma WHO Classification of tumours of the Digestive System, 4th Edition, International Agency for Research on Cancer. Lyon. 2010: 348-402.

36. Dhumeaux D, Marcellin P, Lerebours E (2003) Treatment of hepatitis C. The 2002 French consensus. Gut. 52: 1784-1787.

37. Myers RP, Regimbeau C, Thevenot T, Leroy V, Mathurin P, et al. (2002) Interferon for interferon naive patients with chronic hepatitis C. Cochrane Database Syst Rev 2: CD000370. [Crossref]

38. Kamal SM, Madwar MA, Peters T, Fawzy R, Rasenack J (2000) Interferon therapy in patients with chronic hepatitis $\mathrm{C}$ and schistosomiasis. J. Hepatol 32: 172-174. [Crossref]

39. Kamal SM, El Tawil AA, Nakano T, He Q, Rasenack J (2005) Peginterferon alpha-2b and ribavirin therapy in chronic hepatitis $C$ genotype 4 : impact of treatment duration and viral kinetics on sustained virological response. Gut 54: 858-866. [Crossref] 
40. Misdraji J (2014) Changing indications for liver biopsy: viral hepatitis. Diag histopathol 20: 119-124.

41. Breban R, Arafa N, Leroy S, Mostafa A, Bakr I, et al. (2014) Effect of preventive and curative interventions on hepatitis $C$ virus transmission in Egypt (ANRS 1211): a modelling study. Lancet Glob Health. [Crossref]

42. Mohd Hanafiah K, Groeger J, Flaxman AD, Wiersma ST (2013) Global epidemiology of hepatitis $\mathrm{C}$ virus infection: new estimate of age-specific antibody to $\mathrm{HCV}$ seroprevalence. Hepatology 57: 1333-1342. [Crossref]

43. Ayoub HH, Abu-Raddad LJ (2016) Impact of treatment on hepatitis C virus transmission and incidence in Egypt: A case for treatment as prevention. Journal of viral hepatitis 31: 12671.

44. Deuffic-Burban S, Schwarzinger M, Obach D, Mallet V, Pol S, et al. (2014) Should we await IFN-free regimens to treat HCV genotype 1 treatment-naive patients? A costeffectiveness analysis (ANRS 95141). Hepatology 61: 7-14. [Crossref]

45. Afdhal NH (2012) Fibroscan (transient elastography) for the measurement of liver fibrosis. Gastroenterol Hepatol 8: 605-607. [Crossref]

46. Castera L, Vergniol J, Foucher J, Le Bail B, Chanteloup E, et al. (2005) Prospective comparison of transient elastography, Fibrotest, APRI, and liver biopsy for the assessment of fibrosis in chronic hepatitis C. Gastroenterology 128: 343-350. [Crossref]

47. Hou J, Wang G, Wang F, Cheng J, Ren H, et al. (2017) Guideline of Prevention and Treatment for Chronic Hepatitis B (2015 Update). J Clin Transl Hepatol. 28: 297-318. [Crossref]

48. World Health Organization (2018) Schistosomiasis fact sheet.
49. World Health Organization. (2016) Egypt leverages domestic funding to eliminate schistosomiasis.

50. Vergani D, Mieli-Vergani G (2008) Aetiopathogenesis of autoimmune hepatitis. WJG 14: 3306-3312. [Crossref]

51. de Ledinghen V, Vergniol J, Foucher J, Merrouche W, le Bail B (2012) Non-invasive diagnosis of liver steatosis using controlled attenuation parameter (CAP) and transient elastography. Liver Int 32: 911-918. [Crossref]

52. Cales P, Laine F, Boursier J, Deugnier Y, Moal V, et al. (2009) Comparison of blood tests for liver fibrosis specific or not to NAFLD. J hepatology 50: 165-173. [Crossref]

53. Poynard T, Ratziu V, Charlotte F, Messous D, Munteanu M (2006) LIDO Study Group CYTOL study group. Diagnostic value of biochemical markers (NashTest) for the prediction of non-alcohol steatohepatitis in patients with non-alcoholic fatty liver disease. BMC gastroenterol 10: 6-34. [Crossref]

54. Dienes HP, Drebber U (2010) Pathology of immune-mediated liver injury. Dig Dis 28: 57-62. [Crossref]

55. Corpechot C, El Naggar A, Poujol-Robert A, Ziol M, Wendum D, et al. (2006) Assessment of biliary fibrosis by transient elastography in patients with PBC and PSC. Hepatology 43: 1118-1124. [Crossref]

56. Ryder SD (2003) Guidelines for the diagnosis and treatment of hepatocellular carcinoma (HCC) in adults. Gut 52: 1-8. [Crossref]

Copyright: $@ 2018$ Hassanein M. This is an open-access article distributed under the terms of the Creative Commons Attribution License, which permits unrestricted use, distribution, and reproduction in any medium, provided the original author and source are credited. 